\title{
INVESTIGACIÓN/RESEARCH
}

Recibido: 17/11/2015 --- Aceptado: 28/01/2016 --- Publicado: 15/03/2016

\section{NO SOLO DE PAN VIVE EL HOMBRE}

\author{
Nohemí Fernández Mojica 1: Universidad Veracruzana. México. \\ nfernandez@uv.mx
}

María Esther Barradas Alarcón: Universidad Veracruzana. México. ebarradas@uv.mx

\section{RESUMEN}

En el cuarto pilar de la educación: aprender a ser, está escrito que: [...]"la educación debe contribuir al desarrollo global de cada persona: cuerpo y mente, inteligencia, sensibilidad, sentido estético, responsabilidad individual, espiritualidad. "Todos los seres humanos deben [...] dotarse de un pensamiento autónomo y crítico y de elaborar un juicio propio, para determinar por sí mismos qué deben hacer en las diferentes circunstancias de la vida". (Delors, 1994). Alexander $(2013: 115,120)$, autor del libro: La prueba del cielo, escribió que [...]"el hecho de tomar decisiones correctas frente al mal y la injusticia en la Tierra sería menos significativo si recordáramos toda la belleza y la luz de lo que nos espera cuando salgamos de aquí." [...] todos deberíamos hacer cuanto esté en nuestra mano por ponernos en contacto con esa parte milagrosa de nosotros mismos, a fin de cultivarla y sacarla a la luz. Porque es un ser que está adentro de nosotros mismos ahora mismo y, de hecho, es el ser que Dios espera que seamos". Por su parte, Torralba (2010:51) desde el punto de vista religioso, escribió que ésta [...] es una manifestación, un desarrollo de la inteligencia espiritual [...] que son objeto de fe....da sentido a la vida humana y permite comprender los grandes momentos de la existencia: eventos como el nacimiento, la muerte, el amor y el sufrimiento." En la UV se forma al estudiante en cuatro aspecto, uno de ello es la formación humana entendida desde las dimensiones: emocional, espiritual y corporal.

\section{PALABRAS CLAVE}

Formación integral- espiritualidad- maestros - Dios- fe- inteligencia espiritualmilagros- .

\section{NOT BY BREAD ALONE DOES MAN LIVE}

\footnotetext{
1 Nohemí Fernández Mojica: Universidad Veracruzana. México nfernandez@uv.mx
} 


\begin{abstract}
In the fourth pillar of education: learning to be, it is written that: [...] "Education must contribute to the overall development of every person, body and mind, intelligence, sensitivity, aesthetic sense, personal responsibility, spirituality. "All human beings should [...] be provided with an independent and critical thinking and develop their own views, to determine for themselves what to do in different circumstances of life." (Delors, 1994). Alexander (2013: 115, 120), author of the book: The taste of heaven, wrote that [...] "the fact to make good decisions against evil and injustice on Earth would be less meaningful if we remembered all the beauty and light what awaits us when we leave here. "[...] we should do everything in our power to get in touch with the miraculous part of ourselves, to cultivate and bring it to light. Because it is a being within ourselves now and, in fact, is the being that God expects us to be. " Meanwhile, Torralba (2010: 51) from the religious point of view, wrote that it [...] is a manifestation, a development of spiritual intelligence [...] that are the subject of faith....it gives meaning to human life and it allows us to understand the great moments of existence: events such as birth, death, love and suffering" in the UV the students are formed in four aspects, one of them is human formation understood from the dimensions: emotional, spiritual and body.
\end{abstract}

\title{
KEYWORDS
}

Training teachers integrally spirituality - God faith spiritual intelligence miracles.

\section{INTRODUCCIÓN}

En el cuarto pilar de la educación: aprender a ser, está escrito que: [...]"la educación debe contribuir al desarrollo global de cada persona: cuerpo y mente, inteligencia, sensibilidad, sentido estético, responsabilidad individual, espiritualidad. Dotar [...] de un pensamiento autónomo y crítico y de elaborar un juicio propio, para determinar por sí mismos qué deben hacer en las diferentes circunstancias de la vida". (Delors, 1994). Se cuestionó ¿Los profesores de la Facultad de Pedagogía poseen creencias espirituales que les permitan orientar a los estudiantes ante las circunstancias de la vida?

\section{METODOLOGÍA}

Enfoque cualitativo. Tipo de investigación: Estudio de caso cualitativo, Técnica: entrevista a profundidad. Muestra de caso - tipo: integrada por 10 profesores de la Facultad de Pedagogía - Veracruz de la Universidad Veracruzana. Técnica para la recopilación de la información: entrevista a profundidad. Técnica para el procesamiento de la información: análisis de contenido. 


\section{ANÁLISIS Y DISCUSIÓN}

En el pasaje bíblico: Tentación de Jesús, esta escrito que Jesús fue llevado por el diablo al desierto para tentarlo ante su necesidad de comer, Jesús respondió y dijo: "Escrito está: No solo de pan vivirá el hombre, sino de toda palabra que sale de la boca de Dios." (De Reina, 1991, 820). Todo ser humano tiene la necesidad de trabajar para tener el sustento de: alimento, agua, ropa, calzado; así como una casa que lo proteja de las inclemencias del tiempo, en ella...un hogar en donde se encuentran sus seres queridos: esposo(a) y los hijos. El trabajo remunerado, permite adquirir las necesidades materiales, pero el hombre por ser tripartita: espíritu, alma y cuerpo (De Reina, 1991,1051) tiene la necesidad de tener: paz, fe, esperanza, consuelo, milagros en su vida, estas últimas necesidades, no se venden y por lo tanto no se pueden comprar. ¿Cómo se adquieren? Los siguientes resultados presentados por categorías dan evidencia de la adquisición que tuvieron diez profesores de la Facultad de Pedagogía- Veracruz de la Universidad veracruzana.

\section{Y será llamado....}

La primera adquisición espiritual, en el caso de algunos profesores, la otorgaron los padres o algún familiar, al asignarle el nombre al hijo o la hija. Por las fechas de nacimientos de estos profesores, la asignación fue acorde al nombre santoral correspondiente a la fecha de nacimiento, registrado en el Antiguo Calendario Galván. En otros casos por la cultura mexicana, la moda o creencias. Los siguientes nombres, son una evidencia de estos casos:En la época que nací era muy común anteponer a cualquier nombre el de "María". Esther por ser un nombre bíblico de una mujer importante.". "Fue mi mamá quien me eligió el nombre, desde que lo escuchó le gustó mucho, además que decía que la persona que se llamaba Esther, de la que ella tomó el nombre, era muy buena, ahora sé que Esther significa, estrella." "Mis padres me dicen que me pusieron Gloria, porque nací el sábado de gloria y Elena por el nombre de mi abuela paterna." Mi nombre "Nohemí" me lo asignó mi abuela paterna. Ella era cristiana y lo tomó del libro de Rut. Mi nombre significa: placentera, dichosa. Así he sido hasta el día de hoy.

\section{Agradecimientos a Dios}

¿Por qué los profesores tienen agradecimientos a Dios? La Dirección General de Asociaciones Religiosas (2015), reporta que en México existen 8, 314 asociaciones religiosas, de ellas, 8,278 son asociaciones cristianas. En algunas de estas últimas, los profesores cimentaron las bases de sus creencias espirituales. Por lo que, está presente el conocimiento que se tiene de: "Dad gracias en todo, porque esta es la voluntad de Dios para con vosotros en Cristo Jesús" (De Reina, 1991, 1051). Estas son algunas de las gracias reportadas por ellos.

Por todo lo que se tiene.

¿Agradecimientos? ...muchos, entre ellos el Don de la Vida, la salud, el tener una familia: un buen esposo, la salud de mis nietos, mis hijos, mi nuera, mi trabajo, el deseo de vivir, el tener proyectos, mi Fe Católica. La dicha de tener a mi mamacita, 
mis hermanos, mi carrera universitaria. El amor incondicional que Dios me tiene, su protección Divina desde muy pequeña. Él está conmigo siempre, en todo lugar y momento, Las Gracias o Dones que me ha dado para poder crecer profesional, personal y espiritualmente, etc. También tengo que agradecerle las dificultades, pruebas y sufrimientos que me ha permitido vivir a lo largo de mi viva pues esto significa que para seguirlo, debo cargar con amor mi Cruz. Esto no ha sido fácil, pero como lo expresa Saulo de Tarso (San Pablo) - Todo lo puedo en aquél que me fortalece- . (Entrevista 2)

En todo ha sido mi fortaleza, la guía de mi vida, mi pronto auxilio en mis tribulaciones, mi fuente de sabiduría a la que acudo cuando no tengo clara alguna situación y siempre ha sido fiel. ... me ha dado la vida, que ha llenado de bendiciones mi existencia, que todo lo que tengo no son por mis méritos, sino que él me ha dado la capacidad para lograrlos, me ha dado más de lo que yo merezco, todo le pertenece y me ha dado muchos dones para que haga buen uso de ellos. (Entrevista 6)

En cada momento de mi vida doy gracias a Dios, por un nuevo día, por el amor, por la salud, por mi trabajo, por estar a mi lado en los momentos gratos, pero sobre todo en los momentos más difíciles y tristes. Siento que he sido bendecida a raudales y los episodios desagradables no se comparan con las bendiciones recibidas en todos los aspectos de mi vida. En todos los sentidos, la oportunidad de vivir, regalarme unos padres, hijos, nietos, laboral, profesional, social, económico, salud, amigas, espiritual y todo lo que se pueda agregar. (Entrevista 1)

...la poliomielitis que de bebé me dio me impidieron caminar, pero gracias a Dios y a mis padres pude llegar a caminar después de más de dieciséis intervenciones quirúrgicas...Papá Dios me bendijo con una hermosa familia, un esposo, me dio el regalo maravilloso de poder ser madre de dos preciosos hijos y tener un bonito hogar; me ha dado el privilegio de tener un trabajo estable, de ser su instrumento para ayudar a muchas personas ...pero el más valioso y maravilloso regalo es haberle conocido a Él a través de su Palabra (Entrevista 3)

Considero que en todo, desde el momento mismo que me seleccionó para formar parte de esta vida, en cada instante de mi existencia, al darme padres ejemplares, hermanos solidarios y comprensivos, a mis amados sobrinos, amigos y compañeros. Me dio luz en el camino en dos ocasiones en que me sentí perdida y atascada en una ruta de difícil acceso. Me acompaña en todos mi viajes, me ha abierto puertas cuando otras personas me las cierran. Durante una cirugía, cuando entré al quirófano me abandoné a su voluntad y entregué mi confianza a él. (Entrevista 4)

Por los alimentos.

Te cuento porque estoy agradecida con Dios. El agradecimiento es en muchas áreas. Porqué Él está en cada aspecto de mi vida: un suceso que podría ser trivial, pero que lo no es para mí, es el siguiente: Cuando mi hijo el mayor tenía como cuatro meses, yo no trabajaba y mi esposo y yo no teníamos dinero, jen mi vida no había tenido esta experiencia! Resulta que un tiempo atrás, una maestra de una escuela particular, me pidió que firmara unos certificados ya que tenía que ser una persona con título. 
Precisamente cuando teníamos la necesidad económica, nos encontramos en la calle y ella me dio como pago de esas firmas \$200.00. Yo no había esperado nada, pero en ese momento, fueron muy buenos para mí. Me puse muy contenta porque tenía para comprar los alimentos: leche y pan y se resolvió la necesidad. Dios está en cada situación de mi vida, Él lo es todo. (Entrevista 1)

Por la salud.

En mi caso, ....me enfermé de los riñones tuve cálculos en los riñones.... Incluso me habían programado una operación, gracias a Dios no me operaron, con algunos remedios, expulse esos cálculos. (Entrevista 9)

Dios sanó mis ojos. Por muchos años padecí de blefaritis crónicas. Por periodos largos mis ojos estaban enrojecidos y con una especie de escamas. En una ocasión escuché que pasaran al frente del altar las personas que tuvieran alguna enfermedad, pasé, pusieron las manos sobre mí, oraron pidiendo a Dios sanidad y desde esa fecha, estoy sana. (Entrevista 5)

Por mi recuperación posterior a mi primera cesárea (me dejaron un pedazo de placenta), estuve muy grave. (Entrevista 2)

Por milagros

Estando en una campaña de milagros en el Distrito Federal, escuché que el predicador dijo que Dios haría milagro a tres personas con problemas de columna. Vi pasar a dos personas al frente, hicieron el llamado que había otra persona. Me pregunté: ¿soy yo? Hacía años que me dolía la columna y usaba una talonera con aumento, en época de frío me dolía mi columna y dormía en el piso en posición de feto. Pasé, me dijeron que me quitara mis zapatos y extendiera mis piernas, jfue maravilloso! Vi como mi pierna se estiraba hasta alcanzar el tamaño de la otra. No más dolores de espalda. (Entrevista 5)

Yo soy gemela, pero mi hermanita murió como a los 8 meses de nacida, época en que enfermamos las dos de polio ya que había epidemia en mi pueblo, era tiempo de lluvia y mi pueblo quedaba totalmente incomunicado, como una isla. El río creció tanto que entró a la casa, no había manera de salir al doctor. Por secuela de polio no pude desfilar ni salir en bailable. Tuve muchas intervenciones quirúrgicas para llegar a caminar con aparatos ortopédicos muy pesados" ¿Cuál fue el milagro? Al paso de los años, el milagro fue casarme como Dios manda, embarazarme y haber tenido dos hijos. (Entrevista 3)

La recuperación emocional y física de mi esposo cuando el Padre... le impuso las manos y oró por él. Mi esposo sufrió una caída en su trabajo y se lesionó la columna, por lo que estuvo sin poder caminar y casi paralizado cerca de 3 años. (Entrevista 2)

Por la recuperación milagrosa de mi primer hijo. Esta ocurrió cuando después de varios meses de luchar por su salud, visitando varios pediatras, gastando todo nuestro salario, sin poder dormir, finalmente me hinqué en mi casa, eran como las 2 de la tarde y le dije "María Santísima, tú que eres la Madres de Jesús y sabes cómo se ama a un hijo, ya no puedo más. Toma a mi hijo bajo tu cuidado e intercede ante Mi 


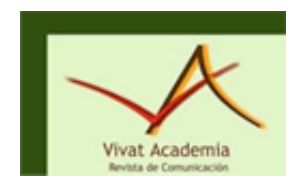

Revista de Comunicación Vivat Academia · Marzo $2016 \cdot$ Año XIX · No 134

ISSN: 1575-2844 ·pp 105-118 · http:/ / dx.doi.org/10.15178/va.2016.134.105-118

Señor Jesús para que se haga su Voluntad." Lloré mucho porque pensé que mi hijo no mejoraría. Para Gloria de Dios, en esa misma tarde, como a las 4, mi bebé empezó a mejorar y a partir de ese momento a la fecha, ha sido muy saludable... A Dios y sólo a Dios Honor y Gloria, mi eterna gratitud. (Entrevista 2)

Otro, En 2002 mi esposo y yo tuvimos un accidente muy fuerte el día de nuestro aniversario de bodas, ... un carro nos pegó estando en espera del siga del semáforo; a pesar de tener el cinturón de seguridad, me proyectó sobre el cofre rompiendo el parabrisas con la cabeza, provocándome tres hernias cervicales con las que he tenido que aprender a vivir. Estando internados los dos en el hospital... como a las 7 de la mañana, llegó un médico a revisarnos a mi esposo y a mí. Estaban nuestros hijos dos varones con nosotros. Mi hijo el menor estaba cuidando a mi esposo y mi hijo el mayor se encontraba conmigo. En estos momentos tuve una especie de revelación (no sé si así se le pueda llamar). En mi mente aparecieron unas palabras como si alguien me las estuviera dictando. Le pedí a mi hijo que escribiera lo que yo le iba a decir, él tomó una receta que tenía en mi bolsa y escribió lo que le dije. Las palabras son las siguientes: “Dos de ustedes son de la estirpe de David y reaccionarán según el Poder del Altísimo". Estas frases aun las tengo escritas en la receta. No sé que significan, pero sin duda es algo hermoso. Tengo otros pasajes en mi vida que Dios me ha dado (Entrevista 2)

Dios me ha dado respuestas inmediatas a algunas oraciones que he hecho en forma sorprendente. (Entrevista 6)

Por la paz recibida.

Mi primer bebé lo perdí por toxoplasmosis. Mi esposo y yo estuvimos muy tristes y angustiados. El médico me recetó un medicamento para ese virus, pero no los había en la ciudad de Veracruz, ni en otras ciudades, ni con los médicos. Oramos y yo y sentí una paz interior muy grande y la certeza que Dios iba al frente de esta batalla. Él me dio una palabra dándome la seguridad que me tendríamos más. Al viajar hacia Xalapa para conseguir el medicamento, por las afueras de Cardel vimos una farmacia en un local muy humilde, mi esposo dudo mucho de encontrar ahí el medicamento, en fin, se bajó a preguntar si tenían el medicamento y ¡cual fue nuestra sorpresa! ; si la hubo!, además, salió con todo el medicamento necesario para el tratamiento de varios meses. Al preguntar porque no lo vendían en otras farmacias, contestaron que era por ser muy barata, un peso la caja de pastillas. (Entrevista 3)

Por logros académicos

Con infinito agradecimiento al Padre Celestial, por tu existencia y fidelidad. Gracias amado, Bendito Dios. (Dedicatoria en la tesis de maestría del entrevistado 3)

¡A ti Señor! Por darme la oportunidad de estar vivo. Por permitirme un cuestionamiento personal, Pensarme con una misión en este mundo. Por tener la posibilidad de reorientar la ruta, de encauzar el río, De corregir los errores y caminar por la vida con un nuevo horizonte. Por darme aquello que otros no tienen, Por valorar quién soy y lo que tengo, por que a pesar de no merecer has estado siempre a 
mi lado, en los momentos difíciles, en las noches obscuras, en las fuertes tormentas, he visto la luz del faro que alumbra y eres tú. Agradezco profundamente tu presencia a mi lado,que me permitas disfrutar este mundo fantásticamente creado por tus manos tal y como expresa David: ¡Oh Señor, nuestro Dios qué grande es tu nombre en toda la tierra! Y tu gloria por encima de los cielos". Salmo 8:1. Gracias por las ganas de vivir, Por hacerme sentir un instrumento de tu grandeza. (Dedicatoria en la tesis de maestría del entrevistado 10)

Al Alto y Sublime que habita en la eternidad. (Dedicatoria en la tesis de maestría del entrevistado 5)

Reconozco que creo al hombre y a la mujer y los unió para formar una familia, dio reglas para la convivencia y desea que vivamos en paz. Es El, el que edifica los hogares. (Dedicatoria en la tesis de doctorado del entrevistado 5)

\section{Creencias}

Los resultados en esta categoría, se presentan desde el enfoque de la definición presentada por Wikipedia: Las creencias religiosas son ideas consideradas como verdaderas por quienes profesan una determinada religión.

La representación que tengo en quien es Dios, como un Padre infinitamente misericordioso, que nos ama con un amor indescriptible, que está al pendiente de mi. De mi familia, que es firme en su disciplina por amor a sus hijos, confía en la obra que somos. Indescriptiblemente la misericordia de perdonarnos, ya que muchas veces la regamos. La sabiduría que pone en nosotros para tomar decisiones. La protección que tiene de nosotros aun cuando nosotros no nos damos cuenta. Maravillosamente espléndido porque cada vez que en oración le he pedido ¡lo que sea!, entre ellos bienes materiales, me lo ha concedido. Siento de el una protección, una comprensión y un amor que lo llena todo. (Entrevista 3)

... yo no tenía conciencia de la existencia de un Dios, en teoría no conocía las Sagradas Escrituras, sabía yo rezar y, en mi ignorancia, ; bendita sea!, siempre creí firmemente en la existencia de alguien que se llamaba Dios, que era en abstracto para mi, el niño Jesús, los reyes magos y la madre de Dios, siempre estuvieron y están presentes en mi vida, y así creo que el hecho de que yo tuviera muy definida mi meta: querer estudiar para ser mejor, leer, trabajar, obedecer ser limpia, honesta, disciplinada, honrada, entonces bajo esos parámetros, ... (Entrevista 2)

He aprendido a encomendar mis proyectos a Dios conforme dice su Palabra: Encomienda a Dios tu camino, confía en él y él hará. Cuando tengo que tomar decisiones, si debo de hacer esto o aquello, siempre pido señal a Dios para saber si es su voluntad o no. (Entrevista 5)

Mi hijo tenía como cuatro meses, yo no trabajaba y mi esposo y yo no teníamos dinero, en mi vida no había tenido esta experiencia. Resulta que un tiempo atrás, una maestra de una escuela particular, me pidió que firmara unos certificados ya que tenía que ser una persona con título. Precisamente cuando teníamos la necesidad económica, nos encontramos en la calle y ella me dio como pago de esas firmas \$ 
200,00. Yo no había esperado nada, pero en ese momento, fueron muy buenos para mí. Me puse muy contenta porque tenía para comprar los alimentos: leche y pan y se resolvió la necesidad. Dios está en cada situación de mi vida, Él lo es todo. (Entrevista 1)

En situaciones de duelo por mi padre, sentí la caricia de Dios en mi cabeza, una flor que abrió en todo su esplendor y muy hermosa, que coloqué delante de la foto de mi padre a dos meses de haber partido. (Entrevista 4)

Dios en su infinita bondad me ha permitido amarlo y buscarlo a través de la oración. Él es mi oxígeno, mi fuerza, mi esperanza, Él es mi creador, mi Luz, Es Mi Dios, Mi Señor, Mi Amado, Mi Todo. Soy adoradora del Santísimo Sacramento, Rezo mi Rosario a María Santísima, a la Preciosa Sangre de Jesucristo, a Las Santa llagas de Jesús, cuando el trabajo me lo permite, asisto a la Santa Eucaristía entre semana y por supuesto los Domingos que es el Día del Señor. (Entrevista 2)

Después de haber sido bautizada por el Espíritu Santo, he notado que tengo la certeza que Dios pone en mi palabra para ayudar al paciente en sesiones de psicoterapia. (Entrevista 3)

Ante situaciones de enfermedad les digo a mis tutorados que tengan fe, que se encomienden a Dios y que le pidan por su familiar, la fe mueve montañas; que los cuiden y que recen mucho por ellos. Que tomen tal producto que por el hecho de tener fe, sanarán" (Entrevista 8)

Procuro a diario leer la Palabra de Dios, por lo regular leo en un promedio 5 capítulos. Siempre encuentro: consejos, esperanza para seguir adelante, consuelo; encuentro palabras que deseo que se me incrusten en mi corazón, las hago mías y se convierten en una realidad, es de creer, de tener fe. (Entrevista 5)

...trato de ser muy responsable en las situaciones que tengo en la vida diaria. El respeto por los demás, el respeto principalmente por mí en la medida que me respeto y respeto a los demás es algo que trato de cuidar muchísimo, de no agredir, porque hay una ley que aprendí muy bien, es la ley de causa y efecto, si le hago algo al de enfrente, al rato voy a pagar, entonces trato de no generar complicaciones para nadie y otros valores como la honestidad, trato de ser entusiasta como un valor, no dejándose llevar por el pesimismo y creer y respetar a Dios. (Entrevista 7)

... nosotros vimos, en el caso de mi papá, que iba a la casa de mi abuelita y le daba dinero, en ese tiempo, cinco pesos diarios, esta cantidad en la década de los 60; o decía: "llévale este bocadito a tu abuelita",... con esta acción, no con palabras, nos enseñó a honrar a los padres. Cuando mis padres envejecieron; entre hermanos nos pusimos de acuerdo y quincenalmente hacíamos una aportación económica, no porque ellos no los pidieran o no tuvieran recursos económicos, jno!, Sino porque sabíamos que esa acción era la voluntad de Dios, y esa acción, se convirtió en bendiciones para nosotros por parte de Dios, y sí que hemos tenido bendiciones porque Lo que nosotros vivimos en el hogar, lo llevamos a su vez a nuestros hogares, gracias a Dios todos vivimos en paz, cada quien con su esposo o esposa y sus hijos. (Entrevista 5) 
Realizo mis devocionales diarios, practico la oración, participo en retos bíblicos, en este momento participo en un reto de lectura de toda la biblia en 2 meses, así como memorización de textos, asisto a una iglesia en la que me congrego y participo junto con mi esposo e hijos. (Entrevista 6)

...una meta fue trabajar dentro del área y trabajar y ganar un ingreso que me permitiera vivir, mas o menos estable, otra de mis metas era tener mi casa, actualmente ya tengo, ahí tienes tu casa y lo logré a base de trabajo, trabajo, ahorro, etc., entonces fueron mis metas, ahorita ya me siento en un ambiente más tranquilo, otra de las metas es terminar la maestría me falta poco tiempo, pero a veces veo los escalones mas alejados mas largos, por que se junta con el trabajo y el resto de las actividades, sin embargo es algo que digo "si lo voy a lograr o primeramente Dios, si lo voy a lograr", y otra meta por ahí muy especial, muy personal que espero en la vida lograr si Dios lo permite, y espero se de. (Entrevista 4)

Tengo la costumbre que al despertar digo: "Bendito sea Dios y Padre de Nuestro Señor Jesucristo que nos bendijo, con toda bendición en los lugares celestiales. Con esto recuerdo que Dios nos ha bendecido y que el día que iniciamos: mi esposo, los hijos, los nietos y yo, lo iniciamos bendecidos por Dios. Oro cubriendo con la sangre de Jesucristo a cada uno de mis seres queridos. Leo un Salmo para que escuche mi hijo, mientras él se cepilla los dientes. En el recorrido a la facultad - 30 minutos- oro, repito en voz alta el salmo 91, 34, 121 y 125 y le pido a Dios para que nos guarde a todos como a la niña de sus ojos. (Entrevista 5)

Diariamente estoy escuchado enseñanzas bíblicas creo que no es suficiente. Cuando me traslado hacia el trabajo, escucho cantos de alabanza y de adoración a Dios. Una vez a la semana dirigí grupos de enseñanza bíblica para mujeres y una vez al mes ofrecí conferencias con contenido psicológico fundamentado en la Palabra de Dios. En las noches oramos en familia. En mi práctica profesional como terapeuta, habituó sugerir antes de llegar a la siguiente sesión, hacer ciertas actividades que van desde escribir una reflexión, leer un capítulo de un libro o una película relacionada con la problemática del paciente y para los que profesan una fe, orar. En el caso de los pacientes el avance de la psicoterapia ha sido significativamente mayor para bien para ellos cuando se comprometen a la oración (Entrevista 3)

...gran parte de mi vida 8 años fueron de convivencia en la iglesia no, entonces en la iglesia pues hacia uno pues todo lo que uno tiene que hacer este asistir, leer la Biblia, este predicar, entonces este eso también me sirvió un poco para ir adquiriendo confianza, el hecho de pararte frente a las personas $i$ no?, a los feligreses y este leer la Biblia y tener que explicar un poco también lo que significaban los pasajes de la Biblia, bueno todo eso daba mucha seguridad, y bueno ya entrada a la universidad sirvió más para que ,este, se fuera uno soltando no con una mayor confianza y seguridad al estar frente a un público no. (Entrevista 10)

Siempre me sentí atraída hacia el misterio de Dios. Cuando me casé, mi esposo y yo entramos a un grupo de encuentros matrimoniales, asistíamos con cierta frecuencia a congresos Eucarísticos de Renovación Carismática, a retiros espirituales de matrimonios. Posteriormente entramos al Movimiento Familiar Cristiano. Aquí 


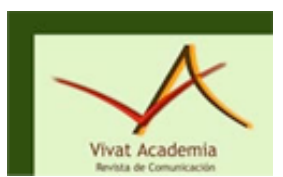

Revista de Comunicación Vivat Academia · Marzo $2016 \cdot$ Año XIX · No 134

ISSN: 1575-2844 ·pp 105-118 · http://dx.doi.org/10.15178/va.2016.134.105-118

coordinamos matrimonios, pláticas para novios próximos a casarse. Tomé un curso de Evangelización liberadora y tuve la oportunidad de participar en las Comunidades de amor donde llevábamos a cabo oraciones comunitarias con cierta periodicidad. (Entrevista 2)

\section{Experiencias espirituales}

Lo que se describe a continuación, se identifica a lo que: “Los más grandes físicos y biólogos de nuestro tiempo identifican en el ser humano un sentido espiritual, una forma de conocimiento y unos niveles de experiencia que no pueden explicarse". (Torralba, 2010, 14)

Algo que marcó mi vida fue el haber tenido a mi primer hijo ¡fue algo maravillosoj: tenerlo en mis brazos y amamantarlo, hasta ahí, yo creí que era lo máximo que yo había vivido, pero, ¡no , lo máximo ha sido ser bautizada por el Espíritu Santo, ¡lo más hermoso en mi vida $i, j$ sentí la presencia de Diosi, sentí, algo que no se puede explicar, sentí gozo, se me escurrieron las lágrimas, $;$ pero de alegría j, de sentir la presencia de Dios. Estaba orando en español y de repente, ¡mi lengua se me trabói no podía orar en español y empecé a orar en otros lenguas, ¡ fue algo maravilloso! (Entrevista 5)

La primera experiencia fue cuando acudí a un grupo de oración - me invitó una maestra -, nos arrodillamos y oramos ... yo tenía solo la experiencia de orar hasta 10 minutos, cuando terminamos de orar y vi el reloj, ¡había pasado 1 hora, 20 minutos orando i y en esa hora 20 minutos fue sorprendente, porque así encuclillada, comencé a cantar un canto que no estaba en mi mente, la letra no es una canción conocida, el timbre, el ritmo tampoco, no era copia de otra melodía, y brotaba de aquí ( se pone la mano sobre el vientre), de mi centro, de mi ser, de aquí del estomago , es lo que está escrito en la Biblia, un cantico nuevo, un cantico dado por el Espíritu, fue algo muy bonito y si, yo lo considero así, sobrenatural, porque yo era muy tímida, no era posible que yo cantara por decisión propia, con personas que yo no conocía y mucho menos encuclillada, $i$ no, no era posible!, fue algo sobrenatural; otra experiencia que marcó mi vida fue cuando con ese grupito de oración viajamos a Monterrey, a una congregación de su misma asociación y pues a mí me consta que no nos dijeron que cuando se entonara tal canto, todos iban a orar en lengua ¿no?. No dijeron nada, proyectaron la letra de los cantos sobre una pared. Empezamos a cantar, de repente.... Zunnnnn (mueve los brazos desplazándolos), ¡Todos orando en otras lenguas!... se me escurrían las lagrimas, vibraba todo mi ser. Con mis manos alzadas, yo temblaba sintiendo la presencia de Dios, fue algo que impacto mi vida, me impacto mucho sentir la presencia de Dios. (Entrevista 5)

En una ocasión, sentí presencia de una persona que me guio en un camino largo en donde no encontraba el lugar que buscaba y en otra ocasión me ayudó a salir de un camino de terracería donde mi carro se atascó, la persona a caballo desde lo lejos me dio indicaciones sobre cómo mover el volante para salir, después de que salí, volví mi vista atrás y ya no había nadie." (Entrevista 4) 


\section{Bases doctrinales}

En esta categoría se encontró que los diez profesores tienen en común como base doctrinal la Biblia, considerada por ellos como la Palabra de Dios.

Las base...Dios Padre, Hijo y Espíritu Santo, que Dios es poderoso y que tenemos como intercesor a su hijo Jesucristo, que el Espíritu Santo nos da la conciencia de lo que hacemos, mi formación ha sido bautista a lo largo de 30 años. (Entrevista 6)

La base de doctrinal son: la Trinidad: Dios Padre, Dios Hijo y el Espíritu Santo; el evangelio del Señor Jesucristo; bautizo en agua como señal de arrepentimiento, bautizo por el Espíritu Santo como señal fluye uno o varios dones otorgados por el Espíritu Santo: sanidad divina, orar en otras lenguas, milagros, profecías, palabras de ciencia, palabra de sabiduría, fe. El bautismo por fuego, la resurrección de los muertos, el arrebatamiento de la iglesia, la gran tribulación, el juicio de Dios, el milenio y las bodas del Cordero. (Entrevista 5)

Amar a Dios sobre todas las cosas, amar al prójimo como a mí mismo, honrar a mis padres, respetar a mis mayores, servir a los demás con amor, respeto y profesionalismo, tener fe y confianza en Dios. (Entrevista 4)

Evidencias físicas de las creencias

1. Al observar los cubículos de algunos de los diez profesores entrevistados, se ven las evidencias de sus creencias espirituales ya que tienen: cuadros con alguna oración o texto bíblico. Calendario con mensajes bíblicos, cuadro con imágenes alusivas a pasajes bíblicos. Objetos como tazas con mensaje bíblico y la Biblia.

\section{CONCLUSIONES}

Por las categorías detectadas de las entrevistas realizadas a los diez profesores se puede concluir:

Los nombre personales se asignaron según la cultura, gusto y creencias de los familiares de los pequeños.

El agradecimiento a Dios, lo lleva a cabo por el conocimiento bíblico de dar gracias por todo lo que se recibe.

De las creencias reportadas, éstas coinciden con la descripción que presenta Barrientos $(2013,7)$ con respecto a "creer" que es: “... el deseo de ingresar a una nueva dimensión con el Espíritu Santo en un proceso de liberación interior, prosperidad del alma y sanidad física. Un lugar donde lo imposible y el desánimo son desechos."

De acuerdo a Tierno ( 2013,33), Si actuamos, pensamos y sentimos con respecto a unas creencias y a un conjunto de normas morales que consideramos "buenas" y compartidas por la gran mayoría de la gente que nos rodea, nos sentiremos satisfechos y el estrés y la ansiedad, la tristeza y el sentimiento de culpa descenderán 
hasta casi desaparecer. Viviremos correctamente y sentiremos la dicha de existir de una manera coherente.

Las creencias evidencian que los diez profesores no son ciegos espirituales ya que sus creencias, no son acorde a lo declarado por... nuestra ceguera a todo lo que no sea el progreso exponencial en la ciencia y en la tecnología nos ha dejado a muchos de nosotros vacíos en el reino del significado y la dicha, sin saber cómo encajan en nuestras vidas en el gran tapiz de la existencia para toda la eternidad. (Alexander, 2013, 204)

En relación a las experiencias espirituales, Torralba $(2010,176)$ al respecto comenta que: Tanto en su interior como el exterior, el ser humano puede hallar indicios de algo que está por encima de él y de todo lo demás, y de lo que él y todo lo demás dependen. La pregunta acerca de ese Ser, la búsqueda del sentido último, pertenece a la esencia del hombre. La espiritualidad es precisamente está búsqueda... Rober Emmons (citado por Torralba, 2010,47) diría que las experiencias de los profesores, se debe al desarrollo de su inteligencia espiritual ya que la define como "aquella capacidad que abarca la trascendencia del hombre, el sentido de lo sagrado y los comportamientos virtuosos. ... la concibe como el uso adaptativo que hacemos de la información espiritual para facilitar la vida de todos los días, resolver problemas cotidianos y conseguir la realización de nuestros propósitos.

Por otra parte, estas experiencias se relacionan con lo que está escrito en el libro de Los Hechos 2:4 "Y fueron todos llenos del Espíritu Santo y comenzaron a hablar en otras lenguas, según el Espíritu les daba que hablasen."

Los relatos de los profesores evidencian lo que el neurocirujano Eben Alexander (2013: 215) describe en su libro: La prueba del cielo. “Comunicarse con Dios es la experiencia más extraordinaria que se pueda imaginar, pero al mismo tiempo es la más natural del mundo, porque Dios está presente en todos nosotros en todo momento. Omnisciente, omnipotente, personal... y fuente de amor incondicional. Todos estamos conectados como uno solo a través de nuestro divino enlace con Dios."

En relación a la creencia de orar, Tierno $(2011,28)$ comenta que: La oración nos satisface, nos completa, porque realmente nos llena de comprensión, de una comprensión no racional, intuitiva y que necesita del concurso de la fe, pero que tiene maravillosas consecuencias: plenitud, paz, tranquilidad...

Los profesores poseen experiencias para compartir con los estudiantes qué deben hacer ante las circunstancias de la vida.

\section{BIBLIOGRAFÍA}

Libros completos: 
Alexander, Eben (2013) "La prueba del cielo. El viaje de un neurocirujano a la vida después de la vida". Traducción: Manuel Mata Álvarez - Santillano. España: Planeta.

Barrientos, Marco (2013) “¡Cree. Todo es posible! Estados Unidos: Casa Creación”

De reina, C, (1991) “La Biblia Devocional de Estudio”. México: La Liga Bíblica

Tierno, Bernabé. (2011)." Espiritual mente. Conecta pensamiento y espíritu para alcanzar el bienestar". España: Ediciones Planeta Madrid.

Maturana Romesín, Humberto (2010) "El sentido de lo humano". Con la colaboración de Argentina: Granica

Torralba, Francesc. (2010). "Inteligencia espiritual. Vivimos en un desierto espiritual”. Primera edición. España: Plataforma Editorial.

\section{Artículos en papel y electrónicos:}

Dirección General de Asociaciones Religiosas (2015)

http://www.asociacionesreligiosas.gob.mx/work/models/AsociacionesReligiosas/pdf/Nu meralia/AR_por_tradicion.pdf consultada el 30 de mayo de 2015

Wikipedia ( 2015) "Creencia religiosa".

https:/ / es.wikipedia.org/wiki/Creencia_religiosa consultada el 12 de junio de 2015

\section{Autores}

\section{Dra. Nohemí Fernández Mojica}

Doctora en Educación, Maestra en Planeación y Desarrollo Educativo, Licenciada en Pedagogía. Pertenece al Sistema Nacional de Investigadores de CONACYT (SNINivel-I) Responsable del C A: "Desarrollo Humano: investigación e intervención educativa". Profesora de tiempo Completo Titular " $\mathrm{C}$ " de la Universidad 
Veracruzana, autora del libro: Instrumentos de evaluación en la investigación educativa. Trillas.

\section{Dra. María Esther Barradas Alarcón}

Doctora en Educación, Maestra en Psicología Clínica, Licenciada en Psicología .Pertenece al Sistema Nacional de Investigadores de CONACYT (SIN- Nivel 1) Responsable del CA: Investigación e intervención en psicología, de la Facultad de Psicología - Veracruz. Profesora de Tiempo Completo titular "C" de la Universidad Veracruzana. Autora de siete libros entre ellos: Prevalencia de depresión en estudiantes universitarios de México. Seguimiento de egresados. Una excelente estrategia para garantizar una educación de calidad. 